\title{
La leyenda de la creación
}

\section{The legend of Creation}

SADEGH HEDAYAT

Traducción, introducción y notas de Shekoufeh Mohammadi Shirmahaleh Translation, introduction and notes by Shekoufeh Mohammadi Shirmahaleh

RESUMEN: Sadegh Hedayat es una de las más influyentes figuras de la literatura persa moderna y contemporánea. Desde una mirada muy crítica, su obra dramática La leyenda de la creación, toca temas importantes de la sociedad iraní de los principios del siglo XX, como el colonialismo, la religiosidad y el tradicionalismo.

ABSTRACT: Sadegh Hedayat is one of the most influential figures of Persian modern and contemporary literature. From a very critical point of view, his dramatic work The legend of Creation, points out important issues of the Iranian society of the beginnings of the twentieth century, such as colonialism, religious beliefs and traditionalism.

Palabras ClaVE: Sadegh Hedayat, Afsāne-ye Äfarīneš, drama en Irán, literatura persa moderna, literatura persa contemporánea.

KEYwords: Sadegh Hedayat, Afsāne-ye Äfarīneš, Drama in Iran, modern Persian literature, contemporary Persian literature.

RECIBIDO: 23 de mayo de 2018 • ACEPTADO: 12 de junio de 2018 



\section{Introducción de la traductora}

Sadegh Hedayat (1903-1951) es considerado uno de los padres de la prosa moderna de Irán y heredero de los intelectuales que motivaron e idearon la revolución constitucional iraní de 1907. Hedayat fue de los primeros escritores que introdujo el género de la novela en Irán, y es conocido además por sus traducciones, ensayos y críticas. Sus obras literarias se consideran de las más brillantes e influyentes de la historia de Irán.

Otro género literario, muy poco desarrollado en Irán en la época de Hedayat, era el drama, y él se convirtió en los primeros escritores en realizar el ejercicio de la dramaturgia. La leyenda de la creación (Afsāne-ye Äfarīneš, 1931) es su última obra dramática y un claro reflejo, no solo de la personalidad misma del autor, de su pensamiento crítico, su rechazo a la autoridad de las religiones y de su humor oscuro y afilado, sino, también, del contexto sociopolítico del Irán de su tiempo.

La leyenda de la creación es una obra sumamente crítica del sistema político del Irán de las primeras décadas del siglo xx, cuando el colonialismo soviético y británico todavía estaba estrangulando al país; los corruptos y caprichosos reyes Qayar habían abandonado al pueblo para dedicarse a sus viajes por Europa a cambio de concesiones territoriales e industriales a los extranjeros, y las voces que exigían libertades, autonomía y derechos, eran violentamente apagadas.

Los personajes de la obra incluyen a Dios, a los arcángeles, al diablo y a Adán y Eva: se trata de una alegoría de la situación sociopolítica de Irán a través del mito de la creación y el pecado original en el Corán. En la obra, los administradores de la corte celestial (los ángeles) tienen nombres que recuerdan la descendencia turca de la dinastía Qayar y el nombre de su rey (Dios) aparenta ser de origen ruso; solo el ángel de la muerte tiene un título religioso islámico, lo cual dice mucho sobre el papel del clero en este periodo histórico como cómplice de la violencia y el asesinato. Los ángeles aparecen como meros súbditos que solo han de obedecer, bajo la amenaza de ser expulsados del paraíso; y el gobernante máximo, como un viejo cascarrabias con mucho poder, que no sabe cómo utilizar. A su vez, los demás habitantes del paraíso son retratados por Hedayat como seres lujuriosos; en una de las primeras 
escenas, la canción que cantan los bailarines de la corte celestial es la parte inicial de una canción revolucionaria constitucionalista, que nos hace pensar en el olvido de los ideales revolucionarios y de cómo éstos han perdido su verdadero sentido. El hecho de que los músicos de la obra estén tocando instrumentos de música tradicional persa puede aludir a la contribución del tradicionalismo a este olvido y pérdida.

Por otro lado, toda la creación parece ser la consecuencia de una guerra de egos entre Dios y el diablo, de nombre afrancesado, cuya función en la obra es la del diablo coránico, pero enfocada desde la perspectiva de quien avisa y recuerda al ser humano sus derechos, y junto con la resonancia de su nombre recuerda los valores de la Revolución francesa. Los primeros humanos, Adán y Eva, simbolizan al pueblo iraní de aquellos tiempos: un pueblo todavía dormido, aterrado y quejumbroso, que para mejorar su situación solo mira hacia los gobernantes, un pueblo que todavía no cree en sí mismo. Frente a esta esperanza de apoyo y socorro, es notable la postura del Dios de la obra: una clara indiferencia, inmadurez e incluso impotencia. Sin embargo, el final de la historia parece esperanzador: Adán y Eva, convencidos de que jamás volverán al paraíso y a sabiendas de que no recibirán ningún apoyo desde arriba, se ocultan de los ojos de los espectadores para hacer el amor. Esta última imagen es una invitación a la reconciliación del pueblo consigo mismo para que tome su destino en sus propias manos.

Ahora bien, además de esta lectura política, la obra se podría analizar desde la clara postura que Hedayat siempre mantuvo en contra de las religiones monoteístas, especialmente el islam, como sistemas opresores que fomentan la superstición y la ignorancia y justifican la violencia y la represión de los monarcas. De esta manera, La leyenda de la creación es también una sátira de las religiones, especialmente las oficializadas, en la que los conceptos de lo sagrado, la justicia, la sabiduría y la divinidad están totalmente ausentes. El verso de Hafez que abre la obra, resume esta misma perspectiva, además de destacar la importancia del ser humano como aquel que ha de perdonar los errores del creador y vivir su vida sin él.

Otro punto destacable de la obra es su subtítulo, "títeres en tres actos". Las descripciones de las escenas, de los personajes y del vestuario salen del marco de un teatro de títeres, pero sería imposible pensar en 
escenificarla como tal con estas características. Lo único que podría justificar el subtítulo es darle una interpretación simbólica: en Irán, “el teatro de títeres" se entiende como una alegoría muy común del espectáculo político. En otras palabras, los políticos son percibidos como títeres movidos por fuerzas trasnacionales, coloniales e imperialistas y el ejercicio de la política, como un espectáculo teatral para el pueblo; un espectáculo que oculta las verdades, las disfraza, y no involucra al espectador, lo excluye y le da un solo lugar: el de quien observa y no hace nada.

Por último, merece advertir que el imaginario de la obra en gran parte se inscribe en el imaginario popular iraní en la época Qayar. Solo en la descripción de los miembros de la corte celestial se adopta el imaginario occidental, pues en Irán no existe la tradición de pensar figurativamente en dios, en el diablo o en los ángeles. Las descripciones de los recintos y en algunos casos del estado de ánimo de los personajes presentan aspectos poéticos y metafóricos que tienen sus raíces en la poesía persa clásica.

HEDAYat, Sadegh (1931). Afsāne-ye Āfarīneš [La leyenda de la creación]. París, Adrian Meson. Nov. 



\title{
SADEGH HEDAYAT
}

\section{La leyenda de la creación}

\section{Títeres en tres actos}

Nuestro Guía dijo: "la pluma del Creador no cometió error alguno".

¡Benditos sus ojos puros que ignoran los errores!

Hafez

\author{
Personajes: ${ }^{1}$ \\ Jaliqov \\ Guibrail Pasha \\ Mikail Efendi \\ Mulá Izrail \\ Israfil Beg \\ Monsieur Sheitán \\ Baba Adam \\ Nane Hawá \\ Huríes, ${ }^{2}$ Guelmanes, ${ }^{3}$ elefante, avestruz
}

$1 \quad$ El autor inventa los nombres de los personajes combinando palabras persas con sufijos y títulos relacionados a distintas lenguas que se refieren a cargos militares o religiosos en las culturas correspondientes y evocan la carga histórica que cada cultura ha tenido en el contexto iraní. Los personajes son: el Creador (Jaliq + sufijo ruso $o v)$, el arcángel Gabriel (+ pasha, título turco otomano), el arcángel Miguel (+ efendi, título turco-bizantino), arcángel Azrael (+ mulá, título árabe), arcángel Israfil (+ beg, título turco), Satán (título del francés), Adán y Eva (con títulos del persa: mamá Eva y papá Adán).

2 Huríes: Mujeres bellísimas que habitan el paraíso según el Corán.

3 Guelmán: variante masculina de hurí. 


\section{ACTO I}

Una glamorosa celebración. En medio, un trono engarzado de joyas y, sentado en él, Jaliqov, con la apariencia de un viejo de espalda doblada con barba larga y cabello cano; lleva puesta una túnica larga y suelta con bordados de oro y lentes gruesas. Se ha apoyado en un cojín bordado de joyas. Un sirviente negro sostiene una sombrilla sobre su cabeza. A su lado, una muchacha blanca lo está refrescando con un abanico.

A los dos lados del trono, los cuatro sirvientes más cercanos de Jaliqov: a la derecha Guibrail Pasha y Mikail Efendi, a la izquierda Mulá Izrail e Israfil Beg. Como soldados romanos, llevan puesta una armadura, cascos y botas hasta la rodilla; están armados con largas espadas atadas a su cintura y en una mano llevan un escudo. Sus alas están dobladas a sus espaldas. Solo Mulá Izrail en lugar de cabeza tiene una calavera, como la de los muertos, lleva una túnica negra y, en lugar de espada, tiene una gran hoz en las manos. Todos ellos están parados en firmes.

Detrás de ellos, un grupo de huríes, con pañuelos cortos en la cabeza y con los ojos y cejas maquillados, miran la fiesta y un grupo de guelmanes las están observando con lujuria. A un lado del recinto, está parado Monsieur Sheitán; es alto, lleva un sombrero cónico, una capa roja y un machete atado a la cintura; tiene barba de chivo y mira la fiesta con las cejas alzadas.

En medio del recinto, un grupo de huries u hadas con ropa ligera, toca la surna, el tombak ${ }^{4}$ y el pandero, y canta:

...el corazón no tiene ganas de pasear por el campo y ver los tulipanes.

No tiene ganas de mirar de cerca la belleza de las flores... 5

Una de las hadas que lleva puesta una falda corta y pantalón, ${ }^{6}$ está bailando en medio. Cuando se termina la canción, se mueve hasta

Instrumentos de aliento (surna) y de percusión (tombak) de la música clásica persa.

Se trata de los primeros versos de una de las más conocidas canciones que compuso el cantautor revolucionario constitucionalista iraní Aref Qazvini (1880-1934).

6 Naser al-din Shá, uno de los monarcas de la dinastía Qayar, en su primer viaje a Europa quedó prendado de la vestimenta de las bailarinas de ballet. Al volver a Irán, ordenó que las mujeres vistieran faldas similares, pero para que no se les vieran las piernas, por cuestiones de tradición religiosa, tuvieron que ponerse un pantalón debajo. Este conjunto se llama Shalité y Shalvar. 
donde está sentado Jaliqov; con mucho coqueteo le tiende una pequeña campana. Jaliqov mete la mano en el chal que usa de cinturón, saca dinero y se lo echa a la campana. Los músicos y cantantes se disponen a empezar de nuevo cuando Jaliqov levanta la mano de repente para ordenarles callar y se pone derecho, como si quisiera levantarse.

JALIQOV.-(Saca un trozo de papel y empieza a leer.) En verdad es así y no es de otra manera que quiero hacer algo de su conocimiento (traga saliva). Saben que a pesar de mi vejez y debilidad física desde hace unos días he puesto manos a la obra. He creado el primer día la luz, después los cielos, las aguas, las piedras, etcétera (se detiene un momento). Ahora, quiero dejarles un recuerdo mío para siempre y así mostrar mi grandeza. Así que, según mi voluntad y poder, he decidido crear sobre esta tierra ubicada en el sistema solar y en la familia del Sol a un grupo de criaturas y después fabricar un rey para ellos y llamarlo "humano", para que sea el gobernante de todas ellas (los presentes manifiestan expresiones de agrado y felicitación). Y quiero que sea no solo el rey de la tierra, sino que también todos los ángeles, genios, ${ }^{7}$ hadas, huríes y guelmanes se dobleguen ante él y le rindan respeto...

MONSIEUR SHEITÁN.-(Interrumpe a Jaliqov y se acerca.) Y entonces ¿dónde quedo yo? ¿De qué sirvo yo?

\section{Los presentes murmuran.}

JALIQOV.-(Su cara se ha vuelto color de frambuesa.) ¿Cómo te atreves a contradecirme? No es asunto tuyo. ¡Cállate!

Monsieur Sheitán.-(Sonriendo.) Yo jamás le haré reverencia a Adán. Yo soy de fuego y él, de tierra.

JALIQOV.-(Se dirige a Guibrail Pasha.) Dale una patada a este imbécil y échalo de aquí.

Monsieur SHeitán._-(Haciendo muecas.) Ya que te pones así, engañaré a Baba Adam; ya verás...

En el Corán, los seres creados por Dios se dividen en tres grupos: los ángeles, los genios y los humanos. Los genios son seres de fuego dotados de voluntad, como los seres humanos. Los ángeles, sin embargo, no tienen libre albedrío. 
Los presentes se hablan en desorden. Guibrail Pasha agarra a satán por el cuello de su ropa, le pega una patada y lo expulsa del recinto. Se escuchan los quejidos de Monsieur Sheitán desde afuera.

JALIQOV.-(Indignado, se dirige a sus cuatro servidores.) Ustedes quédense. Que salgan todos los demás. Anda, de prisa.

Todos los ángeles, huríes y guelmanes salen alicaídos. Un momento de silencio.

JALIQOV.-(Levanta la cabeza.) Guibrail Pasha, ¿tú qué opinas? Apenas quería descansar un poco hoy, después de todo el esfuerzo de la creación. Parece que a este Monsieur Sheitán le he dado demasiada libertad.

Guibrail PASHA.-Sí, señor. Es un grosero irrespetuoso.

JALIQOV.-(Masticando su bigote.) Dado lo ocurrido, y para hacer rabiar más a Monsieur Sheitán, mañana mismo ponemos manos a la obra. Pero ya no quiero verle la cara a este; diré que lo expulsen del paraíso.

GuiBrail PASHA.-Sus palabras son órdenes, majestad.

JALIQOV.-Antes de empezar, quisiera consultarles a ustedes y pedir su opinión.

Los cuatro le hacen una reverencia.

JaliQOv.-(Dirigiéndose a Guibrail Pasha.) Bueno, ¿qué te parece mi plan?

Guibrail PASHA.-Indudablemente está muy bien, pero ¿de qué vivirán estas criaturas que usted hará de barro?

JALIQOV. - Ya lo he pensado. Haré que se maten y se coman.

Guibrail PASHA.-Pero así, su especie no será estable y pronto se extinguirá y el reino de Adán también será efímero, porque ya no le quedarán súbditos. Además, él mismo es de barro y tiene que comer y beber para sobrevivir.

JALIQOV.-Tienes razón. Entonces ¿qué hacemos?

GuIBRAIL PASHA.-Crea estos animales de modo que se reproduzcan y se multipliquen como granos de trigo.

JALIQOV._-¿Qué buena idea! 
Guibrail Pasha.-Pero hay un problema técnico más: puede que lleguen a ser tan numerosos que ya no quepan en la Tierra, o que los más poderosos se coman a los más débiles y un grupo se quede sin comida y se cree un caos.

JALIQOV.-Me acordé de algo. Ayer estaba en el paraíso y vi que el jardinero arrancaba las hierbas del jardín; le pregunté por qué y me dijo que así la tierra conservaría toda su fuerza para alimentar las flores. Nosotros haremos lo mismo.

GuIBRAIL PASHA.-Entonces hay que limitar la vida de estos animales y encargarle a alguien la responsabilidad de matar con frecuencia a un número determinado de aquellas especies que se reproducen demasiado, para así conservar el equilibrio.

JALIQOV.-(Se dirige a Mulá Izrail.) ¡Mulá Izrail!

Mulá IZRAIL.—¿Sí, señor?

JALIQOV._¿Tú puedes encargarte de esto?

MuLÁ IZRAIL.-Por favor, señor; yo estoy viejo, no voy a poder.

JALIQOV.-(Enojado.) ¡Pero, bueno! Hoy todos mis servidores me desobedecen. Primero Monsieur Sheitán y ahora Mulá Izrail. Y yo que pensaba que tenía su apoyo; ¿así me agradecen la confianza?

Mulá IzRAIL.-(Temblando como hojas de un sauce.) Lo siento, señor. Discúlpeme. Lo que usted diga. Por favor le pido, por el cariño que le tiene a Guibrail Pasha, no me expulse del paraíso. Pero ¿cómo puedo llegar yo y quitarles la vida, así de buenas a primeras?

JALIQOV.-Tú no te preocupes. Yo haré que encuentres las excusas necesarias.

Mulá Izrail hace una reverencia. Jaliqov sonríe.

JALIQOV.-(Dirigiéndose a Mikail Efendi.) ¡Mikail Efendi!

MiKAIL EFENDI.-A sus órdenes, señor.

JALIQOV.-Sabes que vamos a tener mucho trabajo; debes poner un despacho y necesitarás algunos contadores y secretarios. Además, las cuentas deben cuidarse mucho. Por cierto, la fuente $\mathrm{Kausar}^{8}$ se había fracturado, ¿la mandaste a reparar?

Según el Corán, una fuente en el paraíso, de la que emana el agua de la vida. 
MiKAIL Efendi.-Sí, señor; mandé a que cerraran la fisura con cal y canto. Todavía no me mandan la factura.

JALIQOV.-Y manda a alguien para que me limpie la oficina y ponlo todo en orden, porque desde mañana mismo voy a empezar a trabajar para que ese Satán se quede ciego de envidia. Y no se te olvide ordenar que nos traigan cinco millones de sacos de arcilla, cinco millones de cubos de agua, cinco millones de moldes, cinco millones de rastrillos, cinco millones de escaleras, cinco millones de hachas, cinco millones de apisonadoras, cinco millones de palas, cinco millones de picos, cinco millones de paletas y cinco millones de tamices, y que lo dejen todo preparado.

MikaIl EfENDI.-Sí, señor. Por cierto, la cúpula de esmeralda está goteando.

JALIQOV.—¿Nos quieres abrumar con más gastos?

MikAIL EFENDI.-Discúlpeme.

JALIQOV.-Ordena que limpien bien el paraíso con agua y escoba; porque he decidido que el ángel que voy a crear a mi imagen y semejanza se quedará en el paraíso para que lo pase bien; sería una pena enviarlo a la tierra con los animales. Pero todos ustedes deben saludarlo.

LOS CUATRO JUNTOS.-(Hacen una reverencia.) Claro que sí.

JALIQOV.-Israfil Beg, ¿por qué tú no dices nada?

ISRAFIL BEG.- ¿Sí, señor?

JALIQOV.-A ti te voy a dar la responsabilidad de ser su cuidador. Debes vigilarlo de cerca para que Satán no lo engañe. Cuando veas que está en peligro, haz sonar tu trompeta. ${ }^{9}$

ISRAFIL BEG.-Sí, señor. Su servidor siempre está a su servicio.

JALIQOV.-Muy bien, me gusta cómo hablas.

ISRAFIL BEG.-Soy su humilde servidor, su servil sirviente.

JALIQOV.-Bueno, y ¿sí podrás hacerlo?

ISRAFIL BEG.-Su Majestad lo sabe muy bien. ¿Acaso no fue hace un par de días, cuando uno de los guelmanes estaba ligando con una de las huríes, que le avisé a tiempo y usted mandó a ambos a las cocinas del infierno?

JALIQOV.-Estoy muy contento con todos ustedes. Pero ninguno es para mí como Guibrail Pasha. Y lo digo cuando él mismo está presente.

$9 \quad$ En el Corán, Israfil es el ángel encargado de anunciar el día del Juicio Final, soplando en su gran trompeta. 
Lo quiero mucho. ¡Ay de mi juventud! Pasamos juntos nuestra juventud. ¡Ay, qué tiempos aquellos!

Guibrail Pasha se mueve como un niño mimoso. Abre sus alas. Mikail Efendi ha recogido una de sus piernas bajo un ala y está dormitando.

JALIQOV.—_Guibrail Pasha!

GuiBrail PASHa.—¿Sí, señor?

JALIQOV.-Confío mucho en ti. Debes ayudarme en todo. (Se dirige a Israfil Beg, Mikail Efendi y Mula Izrail.) Ustedes, váyanse. Que se quede solo Guibrail Pasha.

Guibrail Pasha se queda. Los demás salen.

JALIQOV.-Por fin estamos solos...ve y tráeme un plato de natilla... ¡qué fastidio la vejez!

Guibrail Pasha sale. Jaliqov tose. Cierra los ojos y acerca lentamente los dedos indices de ambas manos. Guibrail Pasha entra con una cazuela. De ella le sirve un plato a Jaliqov y se lo ofrece.

JALIQOV.-(Sonriendo.) Cuando no estabas me consulté a mí mismo. El augurio es bueno.

Guibrail Pasha._- ¿Por qué iba a ser malo? La única voluntad es la de Jaliqov.

Jaliqov se come la natilla a grandes sorbos.

Guibrail PaSha. - Espere que le traiga su babero.

Jaliqov se ríe y al reír sopla la natilla: le salpica a la barba. Guibrail Pasha ríe con tanta fuerza que parece que aúlla.

JALIQOV._- ¡Vaya circo que vamos a montar en la Tierra! Entonces nos sentaremos, los miraremos, comeremos natilla y nos reiremos.

Telón. Se siguen escuchando risas que gradualmente se apagan. 


\section{ACTO II}

Se ve un gran taller. Sobre una mesa estrecha colocada a lo largo del recinto, se pueden ver instrumentos físicos y químicos: microscopio, balanza, máquina eléctrica, compás, escuadra, trozos de madera y grandes contenedores con aguas coloridas. Hay una estufa encendida. Frente al taller han sumergido una gran cantidad de arcilla en agua. Los tamices, paletas, hachas, picos y palas están esparcidos sobre el suelo. Al lado de la mesa hay un sillón frente a un espejo muy grande. Jaliqov se ha subido las mangas. Ha metido la parte inferior de su túnica azul en el chal que usa de cinturón y pasea despacio. Guibrail Pasha tiene una pala en la mano y está mezclando barro.

JALIQOV.-(A Guibrail Pasha.) Pásame este montón de barro.

GuIBRAIL PASHA.-Enseguida. (Enrolla el barro en forma de un cilindro y lo hace rodar hasta dejarlo en medio del recinto. Jadea. Después, limpia el sudor de su frente con la manga.)

JALIQOV.-Te estoy cansando mucho.

GuiBrail PASHA.-No importa en absoluto.

JALIQOV.- Yo mismo me siento cansado. Sabes, hoy es el sexto día que estamos trabajando. El cuarto día hice las plantas, el quinto, los animales. Hoy, con todo lo que sobraba haré el elefante: un animal enorme que tendrá aquí la cabeza y allá (señala lejos) las piernas. Y he apartado parte de la buena arcilla para hacer a Adam. Pensé crear el elefante con todo lo que ha sobrado y después completar la creación de Adam. Y al séptimo día, nos sentamos a mirar.

GuIBRAIL PASHA.-Parece que hacer estos últimos es más fácil. Quería decir algo, pero no sé si decirlo...

JALIQOV.-Di.

GuIBRAIL PASHA.-Se acuerda que cuando estaba creando los microbios y los insectos todo era muy difícil, mucho más que hacer al hombre. Trabajó en ellos con tanta minuciosidad, con lupa y pequeñas agujas. Pero esto de ahora es más sencillo.

JALIQOV. - Vaya... la culpa es mía por haberte mostrado cómo trabajo; y ¿ahora criticas la obra de mi taller? Eres tonto. Si primero los hice a ellos era como práctica. ¿Crees que es fácil hacer al hombre? ¿Acaso 
no viste que hace una hora, frente al espejo, creé a los simios a mi imagen para obtener experiencia y hacer mejor al hombre?

GuIBRAIL PASHA.- ¿Y qué ordena que haga ahora?

JALIQOV.- Tráeme aquellos cuatro troncos de árbol que están en esa esquina.

GuIBRAIL PASHA._-¿Para las piernas del elefante?

JALIQOV.-Muy bien; veo que por fin fluye tu inteligencia.

Guibrail Pasha trae los troncos y los sumerge en el barro.

JALIQOV.-Ahora ven y mételos en las cuatro esquinas de este montículo de barro. (Señala el montículo.) Trae también su cabeza y pégala a su cuello. Dame esta bola de barro. (La señala.)

Guibrail Pasha obedece.

JALIQOV.-(Se ríe.) Guibrail Pasha, se me ha ocurrido una buena idea. Trae el tubo de escape del calentador y mételo en su cabeza - ya es verano y no necesitamos calentador -, y coge dos tortillas de harina del mantel y pégalas a los dos lados de su cabeza. Y, bueno, sabes que los miembros de los animales deben ser simétricos y el miembro que no tiene par se queda en medio.

Guibrail Pasha.-Claro que sí.

Jaliqov se levanta y toma de la mesa una flauta larga. Pone su extremo bajo la cola del elefante. Guibrail Pasha, con la mano en la cintura, observa. De repente, todo el montículo de barro empieza a moverse. Jaliqov quita la flauta y da unos pasos hacia atrás. El elefante mueve su trompa, se levanta y lanza un alto rugido. Jaliqov toma un puñado de alfalfa y se le acerca. El elefante vuelve a rugir, toma el puñado de alfalfa y lo esparce en el aire. Jaliqov, pálido, retrocede.

JALIQOV.-Q Que venga el domador de elefantes y lo meta en un contenedor para enviarlo a la Tierra. 
Llega el domador de elefantes con un pico en la mano. Se sube al elefante y sale del taller. Jaliqov suspira y se deja caer sobre una mecedora. Luego saca su paquete de tabaco y se prepara una pipa. La prende con un cerillo que enciende haciéndolo friccionar bajo su zapato.

JALIQOV.-Guibrail, querido...

GuIBRAIL PASHA.- ¿SŚ, señor?

JALIQOV.-No sabes lo cansado que estoy. Pero temo que si no termino ahora me dé pereza después. Vaya lío en que me metí en plena vejez. Voy a hacer a Adam de una vez, así ya podré estar tranquilo. Me iré a acostar y le diré a una de las huríes que me masajee los pies; tú me traes natilla, miramos la tierra y nos reímos. ¿No te parece bien?

GuIBRAIL PASHA.- Sí, señor.

JALIQOV.-Deshazte de esta mosca. ¡Vaya criatura insistente que he creado! En vez de que se dedique a alabarme, me está agobiando.

Guibrail Pasha.-Señor, échese un poco de agua a la cara. Su barba y bigote están pegajosos por la natilla y las moscas lo han detectado. (Va a por un trozo de cartón, sacude el polvo que lo cubre y empieza a atacar las moscas.)

JALIQOV.-Ahora, acércame el espejo y tráeme la arcilla que he preparado sobre la puerta.

Guibrail Pasha va y trae la puerta sobre la cual está la arcilla que dará forma al hombre.

JALIQOV.-(Se limpia los lentes, mira con asombro. Dice enojado.) ¡Guibrail!

Guibrail Pasha.—¿Sí, señor?

JALIQOV._¿Te atreves a pisar sobre mis huellas? ¿Crees que puedes jugar a ser yo?

GuiBrail Pasha.-Pero no, en absoluto.

JALIQOV.-Entonces, ¿quién le ha dado forma a este barro?

Guibrail Pasha.- - No sabría decirle...

JALIQOV.-Dime la verdad o te vas a arrepentir.

GuiBrail PASHA.-_(Pasa la mano por la frente.) Ah, sí, ahora lo recuerdo. Ayer usted se había quedado dormido en el sillón. Yo entré y vi 
que el mono lo estaba imitando, había cogido una paleta, se miraba en el espejo y le movía al barro. Cuando me vio, escapó. ${ }^{10}$

JALIQOV.-Pues tampoco está mal lo que hizo, pero para que no se vuelva a atrever a imitarme, haré que sus manos sean deformes. Bueno pongamos manos a la obra.

GuiBRAIL PASHA.-Que Dios bendiga al padre del mono por habernos adelantado el trabajo.

JALIQOV.-(Se ríe.) Tráeme la flauta. (Saca su pañuelo de seda y tapa la cara de Adam. Empieza a murmurar algo.)

Guibrail Pasha trae la flauta. Jaliqov la toma y sopla en Adam. Adam se mueve, abre los ojos. Los ángeles y las hadas se abalanzan hacia la puerta del taller y lanzan gritos de halago.

JALIQOV.-(Sonríe con orgullo.) ¡Adam!

Baba Adam se levanta y empieza a aullar.

JALIQOV.-(Se acerca.) Adam, ven hacia mí.

BABA ADAM. - Tengo hambre...tengo hambre... (Frota su barriga.)

JALIQOV.-Acércate. Ven ante mí y hazme reverencia. Primero mandaré a que te laven la cara y el cuerpo, que te peinen. Después, te envío al paraíso para que comas comidas ricas. Pero no comas trigo, ${ }^{11}$ ¿entendido? Si comes trigo vamos a tener problemas. Ordenaré que te expulsen del paraíso.

Baba Adam, con el rostro terrorífico, el cuerpo peludo y los ojos respingones, empieza a golpearse en la cabeza y arrancarse el cabello.

BABA ADAM.-Tengo hambre... tengo hambre... (Señala su estómago con un dedo.)

10 El hecho de que el mono, y no Dios, haya formado al ser humano, hace que nos alejemos de la concepción divina de la creación a favor de la teoría darwiniana de evolución. El comportamiento de Adam y la decepción de Dios en las líneas que siguen confirman esta perspectiva.

11 En el Corán, el fruto prohibido es el trigo. 
Telón. Se sigue escuchando el llanto de Baba Adam y el grito de "tengo hambre".

\section{Aсто III}

Se otea la Tierra: bosques lejanos, montañas, una nube negra en el cielo y la luna asomándose por ella. Se escucha el lejano jaleo de pájaros y otros animales. Grandes criaturas desproporcionadas se asoman entre los árboles. Baba Adam, como los grandes monos, peludo, negro, con una gran panza, ojos inexpresivos y el cabello despeinado, está bajo un árbol de baya junto a Nane Hawá. Nane Hawá tiene el cabello tan largo que roza la tierra; es bajita y tiene la cabeza grande, pómulos rosados, boca grande y pechos y nalgas respingonas. Está estupefacta.

NANE Hawá.-(Se vuelve hacia Baba Adam.) ¡Mira nada más! ¿Viste cómo me imitó el mono? (Se sienta en el suelo y empieza a llorar.)

Baba Adam sacude el árbol. Caen algunas frutas al suelo. Nane Hawá se frota los ojos, recoge la fruta y se la come con ansia. Baba Adam la mira con cariño y sonríe.

NANE HaWÁ.- ¿Qué rico! En el paraíso no había de esta fruta. ${ }^{12}$

BABA ADAM. - ¿Recuerdas lo bien que estábamos en el paraíso? ¡Maldito sea ese Monsieur Sheitán, que nos engañó!

Nane Hawá tiene la boca llena de fruta y tierra. Asiente con la cabeza.

BABA ADAM.-En el paraíso, señalábamos el peral y una pera jugosa se presentaba en nuestra mano. Aquí, tenemos que sufrir para conseguir

12 El árbol de baya es endémico de Irán y muy común, especialmente en las zonas de clima más seco. Es una planta muy importante y de múltiples usos. El hecho de que aparezca en la Tierra de esta obra, refuerza la idea de que esa Tierra es el territorio de Irán. La exclamación de Eva sobre el buen sabor de la fruta es uno de los primeros indicios de que en la Tierra también existe lo bueno y no hay que quedarse esperando y deseando el cielo. 
comida y encima los demás animales compiten con nosotros. ¡Maldito sea Sheitán!

Mientras tanto un gran avestruz se acerca lentamente.

NANE HaWÁ.-(Se levanta rápido.) ¡Maldita sea! ¿Qué es esto? ¡Es enorme!

BABA ADAM. - Este es un avestruz.

NANE HaWÁ. — ¿Avestruz?... ¡Me da miedo!

Baba Adam toma una piedra y se la lanza al avestruz. El pájaro se traga la piedra.

NANE HawÁ._¿ ¿Viste qué hizo? ¡Se comió la piedra! ¡Vaya con Jaliqov y todas las cosas terribles que nos manda! ¡No nos vaya a comer! Anda, trepemos al árbol.

Baba Adam toma a Nane Hawá en brazos y se sube al árbol.

NANE HawÁ.-Tengo miedo. Anoche no pude pegar ojo.

BABA ADAM. - Estábamos mejor en el paraíso. Ahora llamo a Guibrail y le pido perdón a Jaliqov para que nos deje regresar al paraíso, o le pido a Guibrail Pasha el favor de mostrarnos la puerta del paraíso. Y si Jaliqov se niega a perdonarnos, me hago amigo del portero y entramos a escondidas. (Pone las manos a los lados de su boca y grita.) Guibrail... ¡Ey, Guibrail!

Todos los animales guardan silencio. Guibrail Pasha aparece con las alas abiertas, se acerca y saluda a Adam. Adam y Hawá bajan del árbol.

BABA AdAm.-Don Guibrail, perdone que lo haya molestado. Por favor ayúdenos, denos una solución. Salude mucho a Jaliqov de mi parte y pídale disculpas por mí, a condición de que nos deje volver al paraíso. Le juro que no fue culpa mía. Monsieur Sheitán nos engañó. Me dijo: "Come trigo, está rico", y yo comí. No sabía que Monsieur Sheitán y Jaliqov no se llevaban bien. Nosotros no podemos vivir aquí. Mi señora 
Hawá no ha podido dormir anoche. Así no se puede. ¿Por qué nos hizo Jaliqov? Nosotros no se lo habíamos pedido. Y ahora, ¿por qué nos ha mandado a la tierra? ${ }^{13}$

GUIBRAIL PASHA.-Tranquilícense. Él mismo está arrepentido.Anoche estuvo llorando un buen rato y hoy no está de humor. Está tan enojado que nadie se atreve a acercarse a él. Esta misma mañana me ha insultado todo lo que ha podido. Y la culpa de todo la tienen ustedes. Si no hubieran comido trigo, nada de esto habría pasado.

NANE HawÁ.-Don Guibrail, anoche nos metimos en esa cueva. ( $\mathrm{La}$ señala.) Estos animales aullaban. Yo tenía miedo. Hoy le dije a Baba Adam que nos construyera una casa sobre una palma de coco, como los monos. Dile a Jaliqov que nos mande construir un palacio de turquesa, como los que hay en el paraíso.

BABA AdAM.-(A Guibrail Pasha) Por favor, por el amor a quien tú más quieras, haz algo. Déjame a mí, pero haz algo por mi señora Hawá.

GUIBRAIL PASHA.- - No puedo hacer nada.

BABA ADAM.-Entonces dile a Jaliqov que nos convierta en lo que éramos antes. Nosotros no le habíamos pedido que nos creara para mostrar su poder. Y ya que nos ha creado, debe asumir la responsabilidad.

GuiBRaIL PASHA._- ¿Saben? Jaliqov nunca cambia su palabra. Además, si les dice que sí a ustedes, mañana todos los animales van a empezar a pedir.

NANE HawÁ.-(Se muerde la lengua y mira a Adam de reojo.) ¿Blasfemaste otra vez? Don Guibrail, perdónelo. Por favor, no vaya a decírselo a Jaliqov.

Guibrail Pasha.-¡¡Uff! Jaliqov ya tiene el oído lleno de palabras así. El mismo día que empezó a crear supo que el insulto estaría a la orden del día.

NANe HawÁ.-Don Guibrail, usted es una muy buena persona. Me refiero a que es un buen ángel. Le voy a contar algo. Hace rato Baba Adam y yo estábamos aquí y pasó un avestruz ¡Se comió la piedra grande que le lanzamos!

13 Este fragmento permite una lectura filosófica en la que se cuestionan el papel del ser humano en el mundo y se pregunta sobre la función o la responsabilidad de la divinidad en la creación y en su administración. Estos interrogantes ya habían sido formulados por el poeta favorito de Hedayat, Omar Jayyam, en el siglo VIII. 
Guibrail Pasha.-CUstedes se la pasan quejándose de Jaliqov.

BABA ADAM.-Por cierto, ya que estamos a solas, cuéntanos ¿por qué creó Jaliqov a los animales?

Guibrail Pasha._-(Pone el dedo en la boca.) No se lo digas a nadie. Que quede entre tú y yo: ni él mismo lo sabe; está muy arrepentido. Los había creado para sentarse, comer natilla y reírse observándolos.

Nane HawÁ.-No tome en serio lo que Adam le dice. Aquí estamos de maravilla, ni siquiera queremos volver al paraíso. Ahí ese Israfil Beg siempre andaba molestándonos. Cuando hablábamos o nos poníamos a jugar hacía sonar su trompeta. No nos dejaba tranquilos. ¿No es así, Adam?

GuIBRAIL PASHA.-Se ve que poco a poco se están acostumbrando. No estaban contentos ni en el paraíso. Ni aquí lo están. De hecho nunca estarán contentos con nada.

BABA ADAM.-Lo único que me alegra el corazón es Hawá.

NANE HAWÁ.-Yo también te quiero.

Guibrail Pasha repasa a Hawá de pies a cabeza. A Hawá parece que le ha dado vergüenza; corta una hoja de la baya y se tapa con ella.

GuiBrail PASHA._-Para que lleven su vida con más alegría, Jaliqov ha decidido darles hijos.

NANE HaWÁ.-_Hijos? ¿Qué es eso?

GuIBRAIL PASHA. - Una pequeña criatura como ustedes mismos. Una pequeña Hawá o un pequeño Adam. Luego crecerá, ambos lo cuidarán y lo querrán y por él o ella amarán la vida.

BABA ADAM.-Este es otro truco de Jaliqov. No era suficiente con crearnos a nosotros, ahora quiere hacer desgraciados a unos cuantos más. ¿Pero qué pecado hemos cometido?

NANE Hawá.-Jaliqov es más sabio que tú. Don Guibrail, usted tiene razón. Salúdeme mucho a Jaliqov. Jaliqov está en lo cierto. No hace mucho que nos han expulsado del paraíso. (A Adam.) Tú me dejas y te vas por ahí. Yo me quedo sola. Necesito que alguien esté a mi lado, alguien a quien quiera. El avestruz no puede hablar conmigo y tampoco lo quiero.

BABA ADAM.-Menos mal que aprendiste hoy el nombre del avestruz.

Se escuchan gritos desde el cielo: "Guibrail... ;Ey, Guibrail!” 
Guibrail Pasha.-Parece que Jaliqov se ha aburrido otra vez. O quiere su natilla o quiere jugar conmigo a las semillas de durazno y hacer trucos sucios. ¡Vaya destino el mío! Bueno, por el momento, adiós. Si me necesitan, llámenme. (Se echa a volar y se aleja.)

BabA AdAm.-(A Nane Hawá.) Hablaste demasiado. Por más que yo quise arreglar las cosas, no me dejaste. ¡Vaya compañera que me creó Jaliqov! ¡De mi costilla izquierda, para que no estuviera solo!

NANE HaWÁ.-Esto no es cierto. ¿Conque no me quieres? La próxima vez se lo diré a Guibrail Pasha. Si Jaliqov me hubiera dado un hijo no tendría que soportar tus bobadas. ¿Ahora me restriegas en cara tu costilla izquierda? Jaliqov debió dársela a comer al avestruz. Escupo en esta vida... tuf... tuf. (Escupe al suelo, tapa su rostro con ambas manos y empieza a llorar.)

BABA ADAM.-(Le acaricia el cabello.) Ya, tú sabes muchas cosas.

NANE HAwÁ.- Yo pensaba que tú me querías. Ahora veo que estaba equivocada. Siempre me contradices. Huyes de mí con la excusa de encontrar el camino de vuelta al paraíso. Yo me siento sola. Me asustan estos animales. (Se limpia las lágrimas con el dorso de la mano.)

BABA ADAM.-Perdóname, lo dije de broma. Eres muy guapa y te quiero mucho.

NANE HawÁ.-Yo también te quiero. Ya te lo dije una vez delante de Guibrail Pasha. Si tú no estuvieras, yo me moriría de tristeza.

El sol se pone. Aparece la luna con su máscara terrorífica, se ilumina y empieza a subir por el cielo. Un elefante saca la cabeza tras unas ramas y lanza un rugido. Adam y Hawá suben a la baya y Nane Hawá se esconde en los brazos de baba Adam.

BABA ADAM.-Aunque la vida aquí está repleta de sufrimiento, es mejor que la vida monótona del paraíso. Yo en el paraíso me estaba asfixiando. Esa vida de solo comer y dormir cansa mucho. No sé cómo se quedan los ángeles en el paraíso.

NANE HawÁ. - La verdad, qué bueno que nos expulsaron del paraíso. Aquí por lo menos nadie nos vigila y estamos más tranquilos y felices.

BABA ADAM.-Acerca tus labios... felicidad, esto es el objetivo de la creación. 
Baba Adam se acerca a Nane Hawá y la besa con fuerza. Nane Hawá toma una rama del árbol con la mano y tapa a los dos. Ya no se ven. Telón. El rugido de los animales se apaga poco a poco.

París, 8 de abril de 1931 